\section{JURNAL EKONOMI EFEKTIF}

ISSN : $2622-8882$, E-ISSN : 2622-9935

Jurnal Ekonomi Efektif, Vol. 2, No. 4, Juli 2020

@.Prodi Manajemen Fakultas Ekonomi Universitas

Pamulang

\title{
PENGARUH GAYA KEPEMIMPINAN TERHADAP KINERJA KARYAWAN PADA PT. TUNAS SAKTI DI DAAN MOGOT JAKARTA BARAT
}

\author{
Kemas Vivi Andayani \\ Universitas Pamulang, Tangerang Selatan, Banten, Indonesia \\ *dosen01342@unpam.ac.id
}

\begin{abstract}
ABSTRAK
Penelitian ini bertujuan untuk mengetahui pengaruh gaya kepemimpinan terhadap kinerja karyawan pada PT. Tunas Sakti di Daan Mogot Jakarta Barat. Metode yang digunakan adalah explanatory research dengan sampel sebanyak 90 responden. Teknik analisis menggunakan analisis statistik dengan pengujian regresi, korelasi, determinasi dan uji hipotesis. Hasil penelitian ini variabel gaya kepemimpinan diperoleh nilai rata-rata skor sebesar 3,478 dengan kriteria baik. Variabel kinerja karyawan diperoleh nilai rata-rata skor sebesar 3,788 dengan kriteria baik. Gaya kepemimpinan berpengaruh positif dan signifikan terhadap kinerja karyawan dengan nilai persamaan regresi $\mathrm{Y}=11,9661+0,745 \mathrm{X}$, dan nilai koefisien korelasi 0,728 atau memiliki tingkat hubungan yang kuat dengan nilai determinasi 53,0\%. Uji hipotesis diperoleh signifikansi $0,000<0,05$.
\end{abstract}

\section{Kata Kunci: Gaya Kepemimpinan, Kinerja Karyawan.}

\section{ABSTRACT}

This study aims to determine the effect of leadership style on employee performance at PT. Tunas Sakti in Daan Mogot, West Jakarta. The method used is explanatory research with a sample of 90 respondents. The analysis technique uses statistical analysis with regression testing, correlation, determination and hypothesis testing. The results of this study, the leadership style variable obtained an average score of 3.478 with good criteria. Employee performance variables obtained an average score of 3.788 with good criteria. Leadership style has a positive and significant effect on employee performance with the regression equation $Y$ $=11.9661+0.745 X$, and a correlation coefficient value of 0.728 or has a strong level of relationship with a determination value of $53.0 \%$. Hypothesis testing obtained a significance of $0.000<0.05$.

Keywords: Leadership Style, Employee Performance. 


\section{PENDAHULUAN}

\section{A. Latar Belakang Masalah}

Pada era globalisasi perkembangan dan perubahan yang sangat cepat terhadap kemajuan ilmu pengetahuan teknologi, sumber daya manusia, ekonomi, sosial dan budaya suatu bangsa. Sehingga mau tidak mau suatu bangsa harus menghadapi bentuk perubahan. Perubahan yang terjadi ini bukan hanya dihadapi pemerintah saja akan tetapi oleh perusahaanperusahaan baik milik pemerintah ataupun swasta. Dalam pencapaian tujuan tersebut, perusahaan harus mempunyai kemampuan dalam mengkombinasikan faktor-faktor produksi dengan sabaik- baiknya agar perusahaan dapat di tingkatkan semaksimal mungkin. Salah satu faktor terpenting adalah manusia, karena manusia menyimpan potensi, bakat, kemampuan dan semangat yang digunakan dalam pencapaian tujuan perusahaan.

Akan tetapi perubahan seringkali melupakan betapa sumber daya manusia sangat mempengaruhi pencapaian tujuan perusahaan, sumber daya manusia menunjuk kepada setiap individu yang terlibat dalam seluruh kegiatan perusahaan. Tenaga kerja atau karyawan merupakan salah satu aset perusahaan yang memiliki peranan yang cukup besar dalam mencapai tujuan perusahaan. Dalam mencapai tujuan setiap perusahaan sangat memerlukan manajemen yang baik dengan usaha-usaha untuk mencapai tujuan perusahaan. Diantara nya adalah gaya kepemimpinan yang diterapkan pada masing-masing organisasi. Pada satu sisi perusahaan tidak mungkin mengoperasikan kegiatannya tanpa adanya pemimpin, karena faktor tersebut memegang peranan yang penting dalam pencapaian tujuan perusahaan yaitu pencapaian kinerja perusahaan yang baik.

Keberadaan seorang pemimpin dalam perusahaan sangat dibutuhkan untuk membawa perusahaan kepada tujuan yang telah ditetapkan. Berbagai gaya kepemimpinan akan mewarnai perilaku seseorang pemimpin dalam menjalankan tugasnya. Bagaimanpun gaya kepemimpinan seseorang tentunya akan diarahkan untuk kepentingan bersama, yaitu kepentingan pekerjaan dan perusahaan. Perkembangan dan perubahan globalisasi tentunya harus siap dihadapi semua perusahaan swasta maupun milik pemerintah. Akan tetapi perkembangan dan perubahan globalisasi itu sendiri bisa menjadi tantangan bagi perusahaan yang siap menghadapi dan sebaliknya bisa jadi ancaman atau masalah bagi perusahaan yang tidak siap. Ketidak siapan PT. Tunas Sakti inilah yang menyebabkan berbagai ancaman yang muncul sehingga menimbulkan permasalahan-permasalahan baik internal maupun eksternal perusahaan, permasalahan tersebut diantaranya permasalahan antara karyawan dengan pimpinan, karyawan dengan karyawan. Gaya kepemimpinan yang Kharismatik ini merupakan tipe gaya kepemimpinan sebelum adanya perubahan kepemimpinan pada PT. Tunas Sakti. Dan setelah adanya perubahan gaya kepemimpinan yang cenderung dalam memimpin karyawan yaitu tipe gaya kepemimpinan otoriter. Dikarenakan permasalahanpermasalahan tersebut akan dapat mempengaruhi tingkat kinerja karyawan yang dihasilkan untuk perusahaan. Ketidakhadiran dan keterlambatan akan menghambat proses penyelesaian pekerjaan yang benar dan tepat waktu. Kinerja karyawan adalah keluaran yang dihasilkan oleh fungsi-fungsi atau indikator-indikator suatu pekerjaan atau suatu profesi dalam waktu tertentu. Sehingga karyawan dengan penuh kesadaran dan tanggung jawab akan melaksanakan pekerjaan tanpa disuruh atasan. Pemimpin dituntut secara konsisten memperhatikan dan membangun kinerja karyawan. Alasan mengapa kinerja karyawan sangat penting karena seorang karyawan yang mempunyai kinerja yang bagus dan memuaskan diharapkan dapat melaksanakan pekerjaannya dengan optimal dan akan berdampak produktivitas. Untuk mewujudkan sikap kerja karyawan yang baik diperlukan berbagai cara yang dapat dilakukan oleh seorang pemimpin yaitu dengan kepemimpinan yang tepat.

Menurut Prasetio (2006) gaya kepemimpinan adalah cara yang digunakan dalam proses 
kepemimpinan yang implementasikan dalam perilaku kepemimpinan seseorang mempengaruhi orang-orang lain untuk bertindak sesuai dengan apa yng diinginkan. Kurangnya penguasaan pengetahuan majerial pimpinan membuat karyawan merasa tak diperhatikan sebagai karyawan. Sehingga karyawan kurang terbantu dalam menyelesaikan persoalan karyawan yang kurang dimengerti. Sehingga tidak terjalin kerjasama yang baik antara karyawan dan atasan menimbulkan jalinan komunikasi yang kurang baik dalam proses bekerja.

PT. Tunas Sakti merupakan perusahaan yang bergerak dalam bidang penjualan (Sales) dan jasa otomotif (After Sales). Berdasarkan pengamatan sekilas bahwa karyawan yang bekerja diperusahaan tersebut banyak mengalami dan merasakan permasalahan seperti diatas sehingga mereka banyak yang bekerja tidak sesuai dengan SOP yang berlaku pada perusahaan dan bahkan banyak yang melanggar aturan perusahaan.

Berdasarkan pemikiran tersebut maka penulis tertarik untuk mengadakan penelitian, guna memperoleh informasi dan data secara rinci tentang gaya kepemimpinan terhdapat kinerja karyawan. Oleh karena itu penulis mengambil judul penelitian sebagai berikut: "Pengaruh Gaya Kepemimpinan Terhadap Kinerja Karyawan Pada PT. Tunas Sakti Daan Mogot Daan Mogot Jakarta Barat Barat".

\section{B. Rumusan Masalah}

1. Bagaimana gaya kepemimpinan pada PT. Tunas Sakti di Daan Mogot Jakarta Barat?.

2. Bagaimana kinerja karyawan pada PT. Tunas Sakti di Daan Mogot Jakarta Barat?.

3. Adakah pengaruh antara gaya kepemimpinan terhadap kinerja karyawan pada PT. Tunas Sakti di Daan Mogot Jakarta Barat?.

\section{Tujuan Penelitian}

1. Untuk mengetahui kondisi gaya kepemimpinan pada PT. Tunas Sakti di Daan Mogot Jakarta Barat.

2. Untuk mengetahui kondisi kinerja karyawan pada PT. Tunas Sakti di Daan Mogot Jakarta Barat.

3. Untuk mengetahui pengaruh antara gaya kepemimpinan terhadap kinerja karyawan pada PT. Tunas Sakti di Daan Mogot Jakarta Barat.

\section{TINJAUAN PUSTAKA}

\section{Gaya kepemimpinan}

Gaya kepemimpinan PT. Tunas Sakti yang dimaksud menurut Miftah Thoha (2017) adalah suatu norma perilaku yang digunakan oleh seseorang pada saat orang tersebut mencoba mempengaruhi perilaku orang lain atau bawahannya.

\section{Kinerja Karyawan}

Yang dimaksud dengan Kinerja Karyawan menurut Mathis (2016) adalah proses keseriusan kerja secara berkualitas oleh seorang karyawan, dalam penelitian ini PT. Tunas Sakti di Daan Mogot Jakarta Barat

\section{METODE PENELITIAN}

\section{Populasi}

Populasi dalam penelitian ini berjumlah 90 responden PT. Tunas Sakti di Daan Mogot Jakarta Barat 


\section{Sampel}

Teknik pengambilan sampling dalam penelitian ini adalah sampel jenuh, dimana semua anggota populasi dijadikan sebagai sampel. Dengan demikian sampel dalam penelitian ini sampel yang digunakan berjumlah 90 responden.

\section{Jenis Penelitian}

Jenis penelitian yang dipakai adalah asosiatif, dimana tujuannya adalah untuk mengetahui atau mencari keterhubungan antara variabel independen terhadap variabel dependennya

\section{Metode Analisis Data}

Dalam menganalisis data digunakan uji validitas, uji reliabilitas, analisis regresi linier sederhana, analisis koefisien korelasi, analisis koefisien determinasi dan pengujian hipotesis.

\section{HASIL PENELITIAN}

\section{Analisis Deskriptif}

Pada pengujian ini digunakan untuk mengetahui skor minimum dan maksimum skor tertinggi, ratting score dan standar deviasi dari masing-masing variabel. Adapun hasilnya sebagai berikut:

Tabel 1. Hasil Analisis Descriptive Statistics

\section{Descriptive Statistics}

\begin{tabular}{l|r|r|r|r|r} 
& N & Minimum & Maximum & Mean & \multicolumn{1}{c}{ Std. Deviation } \\
\hline Gaya kepemimpinan (X) & 90 & 29 & 48 & 34.78 & 3.877 \\
\hline Kinerja Karyawan (Y) & 90 & 29 & 49 & 37.88 & 3.968 \\
\hline Valid N (listwise) & 90 & & & & \\
\hline
\end{tabular}

Gaya kepemimpinan diperoleh varians minimum sebesar 29 dan varians maximum 48 dengan ratting score sebesar 3,478 dengan standar deviasi 3,877. Skor ini termasuk pada rentang sakala 3,40 - 4,19 dengan kriteria baik atau setuju.

Kinerja karyawan diperoleh varians minimum sebesar 29 dan varians maximum 49 dengan ratting score sebesar 3,788 dengan standar deviasi 3,968. Skor ini termasuk pada rentang sakala 3,40 - 4,19 dengan kriteria baik atau setuju.

\section{Analisis Verifikatif.}

Pada analisis ini dimaksudkan untuk mengetahui pengaruh variabel independen terhadap variabel dependen. Adapun hasil pengujian sebagai berikut:

\section{a. Analisis Regresi Linier Sederhana}

Uji regresi ini dimaksudkan untuk mengetahui perubahan variabel dependen jika variabel independen mengalami perubahan. Adapun hasil pengujiannya sebagai berikut:

Tabel 2. Hasil Pengujian Regresi Linier Sederhana

\begin{tabular}{lr|r|r|r|r} 
& \multicolumn{2}{c}{ Coefficients $^{\mathbf{a}}$} \\
& $\begin{array}{c}\text { Unstandardized } \\
\text { Coefficients }\end{array}$ & $\begin{array}{c}\text { Standardized } \\
\text { Coefficients }\end{array}$ & & \\
Model & $\mathrm{B}$ & Std. Error & Beta & $\mathrm{t}$ & Sig. \\
\hline 1 (Constant) & 11.966 & 2.619 & & 4.570 & .000 \\
\hline Gaya kepemimpinan $(\mathrm{X})$ & .745 & .075 & .728 & 9.956 & .000 \\
\hline
\end{tabular}

Berdasarkan hasil pengujian pada tabel di atas, diperoleh persamaan regresi $\mathrm{Y}=$ $11,9661+0,745 X$. Dari persamaan tersebut dijelaskan sebagai berikut:

1) Konstanta sebesar 11,9661 diartikan jika gaya kepemimpinan tidak ada, maka telah 
terdapat nilai kinerja karyawan sebesar 11,9661 point.

2) Koefisien regresi gaya kepemimpinan sebesar 0,745 , angka ini positif artinya setiap ada peningkatan gaya kepemimpinan sebesar 0,745 point maka kinerja karyawan juga akan mengalami peningkatan sebesar 0,745 point.

\section{b. Analisis Koefisien Korelasi}

Analisis koefisien korelasi dimaksudkan untuk mengetahui tingkat kekuatan hubungan dari variabel independen terhadap variabel dependen. Adapun hasil pengujian sebagai berikut:

Tabel 3. Hasil Pengujian Koefisien Korelasi Gaya kepemimpinan Terhadap Kinerja Karyawan.

\begin{tabular}{|c|c|c|c|}
\hline \multicolumn{4}{|c|}{ Correlations $^{b}$} \\
\hline & & $\begin{array}{c}\text { Gaya } \\
\text { kepemimpinan (X1) }\end{array}$ & $\begin{array}{c}\text { Kinerja } \\
\text { Karyawan (Y) }\end{array}$ \\
\hline \multirow[t]{2}{*}{ Gaya Kepemimpinan (X) } & Pearson Correlation & 1 & $.728^{* *}$ \\
\hline & Sig. (2-tailed) & & .000 \\
\hline \multirow[t]{2}{*}{ Kinerja Karyawan (Y) } & Pearson Correlation & $.728^{* *}$ & 1 \\
\hline & Sig. (2-tailed) & .000 & \\
\hline
\end{tabular}

Berdasarkan hasil pengujian diperoleh nilai korelasi sebesar 0,728 artinya gaya kepemimpinan memiliki hubungan yang kuat terhadap kinerja karyawan.

\section{c. Analisis Koefisien Determinasi}

Analisis koefisien determinasi dimaksudkan untuk mengetahui besarnya persentase pengaruh dari variabel independen terhadap variabel dependen. Adapun hasil pengujian sebagai berikut:

Tabel 4. Hasil Pengujian Koefisien Determinasi Gaya kepemimpinan Terhadap Kinerja Karyawan.

\begin{tabular}{|c|c|c|c|c|}
\hline \multicolumn{5}{|c|}{ Model Summary } \\
\hline Model & $\mathrm{R}$ & R Square & $\begin{array}{l}\text { Adjusted R } \\
\text { Square }\end{array}$ & $\begin{array}{l}\text { Std. Error of the } \\
\text { Estimate }\end{array}$ \\
\hline 1 & $.728^{a}$ & .530 & .524 & 2.737 \\
\hline
\end{tabular}

Berdasarkan hasil pengujian diperoleh nilai determinasi sebesar 0,530 artinya gaya kepemimpinan memiliki kontribusi pengaruh sebesar 53,0\% terhadap kinerja karyawan, sedangkan sisanya sebesar $47,0 \%$ dipengaruhi oleh faktor lain yang tidak dilakukan penelitian.

\section{d. Uji Hipotesis}

Pengujian hipotesis dengan uji t digunakan untuk mengetahui hipotesis mana yang diterima.

Rumusan hipotesis: Terdapat pengaruh yang signifikan antara gaya kepemimpinan terhadap kinerja karyawan.

Tabel 5. Hasil Uji Hipotesis Gaya kepemimpinan Terhadap Kinerja Karyawan.

\begin{tabular}{|c|c|c|c|c|c|}
\hline \multirow[b]{2}{*}{ Model } & $\begin{array}{r}\text { Co } \\
\text { Unst } \\
\text { Co }\end{array}$ & $\begin{array}{l}\text { ficients }^{\text {a }} \\
\text { hdardized } \\
\text { ficients }\end{array}$ & $\begin{array}{l}\text { Standardized } \\
\text { Coefficients }\end{array}$ & \multirow[b]{2}{*}{$t$} & \multirow[b]{2}{*}{ Sig. } \\
\hline & $\mathrm{B}$ & Std. Error & Beta & & \\
\hline 1 (Constant) & 11.966 & 2.619 & & 4.570 & .000 \\
\hline Gaya kepemimpinan (X) & .745 & .075 & .728 & 9.956 & .000 \\
\hline
\end{tabular}


Berdasarkan hasil pengujian pada tabel di atas, diperoleh nilai $\mathrm{t}$ hitung $>\mathrm{t}$ tabel atau $(9,956>1,987)$, dengan demikian hipotesis yang diajukan bahwa terdapat pengaruh yang signifikan atara gaya kepemimpinan terhadap kinerja karyawan diterima.

\section{Pembahasan Hasil Penelitian}

\section{Kondisi Jawaban Responden Variabel Gaya kepemimpinan}

Berdasarkan jawaban responden, variabel gaya kepemimpinan diperoleh ratting score sebesar 3,478 berada di rentang skala 3,40 - 4,19 dengan kriteria baik atau setuju.

\section{Kondisi Jawaban Responden Variabel Kinerja Karyawan}

Berdasarkan jawaban responden, variabel kinerja karyawan diperoleh ratting score sebesar 3,788 berada di rentang skala 3,40 - 4,19 dengan kriteria baik atau setuju.

\section{Pengaruh Gaya kepemimpinan Terhadap Kinerja Karyawan}

Gaya kepemimpinan berpengaruh signifikan terhadap kinerja karyawan dengan persamaan regresi $\mathrm{Y}=11,9661+0,745 \mathrm{X}$, nilai korelasi sebesar 0,728 atau memiliki hubungan yang kuat dengan kontribusi pengaruh sebesar 53,0\%. Pengujian hipotesis diperoleh nilai $\mathrm{t}$ hitung $>\mathrm{t}$ tabel atau $(9,956>1,987)$. Dengan demikian hipotesis yang diajukan bahwa terdapat berpengaruh signifikan antara gaya kepemimpinan terhadap kinerja karyawan diterima.

\section{KESIMPULAN DAN SARAN}

\section{Kesimpulan}

a. Variabel gaya kepemimpinan diperoleh ratting score sebesar 3,478 berada di rentang skala 3,40 - 4,19 dengan kriteria baik atau setuju.

b. Variabel kinerja karyawan diperoleh ratting score sebesar 3,788 berada di rentang skala 3,40 - 4,19 dengan kriteria baik atau setuju.

c. Gaya kepemimpinan berpengaruh signifikan terhadap kinerja karyawan dengan persamaan regresi $\mathrm{Y}=11,9661+0,745 \mathrm{X}$, nilai korelasi sebesar 0,728 atau kuat dan kontribusi pengaruh sebesar 53,0\% sedangkan sisanya sebesar $47,0 \%$ dipengaruhi faktor lain. Uji hipotesis diperoleh nilai $t$ hitung $>t$ tabel atau $(9,956>1,987)$.

\section{Saran}

a. Untuk lebih baik lagi PT. Tunas Sakti harus membangun suasana yang dinamis, pendekatan-pendekatan antar semua lini dan merata disemua karyawan, baik dilakukan secara formal maupun non formal. Bertujuan agar semua karyawan bias disiplin di perusahaan dan 532ias mengembangkan perusahaan.

b. PT. Tunas Sakti harus benar-benar melakukan evaluasi dan pengkajian kembali terhadap setiap tugas dan tanggung jawab yang diberikan kepada karyawan dan pemberian kepercayaan pada setiap karyawan perusahaan.

c. Dalam meningkatkan kinerja karyawan, perusahaan dapat memberikan tugas yang menantang agar karyawan dapat mengembangkan kreativitas didalam melakukan pekerjaannya.

\section{DAFTAR PUSTAKA}

A.A Anwar Prabumangkunegara, 2011. Manajemen Sumber Daya Manusia Perusahaan. PT.Remaja Rosda Karya: Bandung.

Bambang Prasetio, 2006. Metode Penelitian Kuantitatif Teori dan Aplikasi, Raja Grafindo 
Persada: Jakarta.

Brahmasari, Ida Ayu dan Agus Suprayetno, 2008. Pengaruh Motivasi Kerja, Kepemimpinan dan Budaya Organisasi Terhadap Kepuasan Kinerja Karyawan. Vol.10: 124-135.

Edy Sutrisno, 2009.Manajemen Sumber Daya Manusia, Jakarta: Kencana Media Group.

George R. Terry, 2007. Prinsip-Prinsip Manajemen. (edisi Bahasa Indonesia). PT. Bumi Aksara: Bandung.

Handoko, Hani, T. 2010. Manajemen Personalia dan Sumber Daya Manusia Edisi Kedua. Cetakan Keempat Belas. Yogyakarta: BPFE-UGM.

Hasibuan, Malayu, S.P, 2016. Manajemen Sumber Daya Manusia.

Ilham, D. (2019). Implementing Local Wisdom Values in Bride and Groom Course at KUA Bara SubDistrict, Palopo City. Jurnal Konsepsi, 8(1), 1-9.

Ilham, D. (2019). Menggagas Pendidikan Nilai dalam Sistem Pendidikan Nasional. Didaktika: Jurnal Kependidikan, 8(3), 109-122.

James, A.F. Stoner, Bakowaturn, 2012. Manajemen jilid 1 / James A.F. Stoner; alih bahasa Alfonsus Sirait. Penerbit Erlangga: Jakarta.

Kartono, K., 2010. Pemimpin dan Kepemimpinan, Penerbit PT. Rajawali Press: Jakarta.

Marayasa, I. N. (2018). Analisis Kepemimpinan Kepala Desa Sukamulya Kecamatan Rumpin Kabupaten Bogor. JENIUS (Jurnal Ilmiah Manajemen Sumber Daya Manusia), 2(1).

Mathis Robert L. dan Jackson H, 2006.Human Resource Management, Alih Bahasa. Salemba Empat. Jakarta.

Miftah Thoha, 2010. Kepemimpinan dan Manajemen, Devisi Buku Perguruan Tinggi, PT. Raja Grafindo Persada: Jakarta.

Robbins, Stephen P, 2009. Organizational Behavior. 13Three Edition, USA: Person International edition, Prentice-hall.

Sedarmayanti, 2007. Manajemen Sumber Daya Manusia, Reformasi Informasi dan Manajemen Pegawai Negeri Sipil. Cetakan pertama oleh PT. Rafika Aditama: Bandung.

Siagian, Sondang, P., 2010. Manajemen Sumber Daya Manusia, Penerbit Bumi Aksara: Jakarta.

Sudjana, M. A., 2009. Metode Statistik. Penerbit Tarsito: Bandung.

Sugiyono, 2016.Metode Penelitian Administratif. Bandung: Alfabeta.

Sunarsi, D. (2019). Penerapan MSDM Strategis Dalam Upaya Meningkatkan Kemampuan Organisasi dalam menyongsong Revolusi 4.0. Jurnal Ilmiah MEA (Manajemen, Ekonomi, \& Akuntansi), 3(1), 221-233. https://doi.org/10.31955/mea.vol3.iss1.pp221233

Suryani, N. L. (2018). Pengaruh Gaya Kepemimpinan Dan Motivasi Terhadap Kinerja Karyawan Pada PT. Boga Lestari Sentosa (Kenny Rogers Roasters) Indonesia. JENIUS (Jurnal Ilmiah Manajemen Sumber Daya Manusia), 2(1).

Sutrisno, S. (2019). Pengaruh Kepemimpinan Dan Disiplin Kerja Terhadap Kinerja Guru SMP Muhammadiyah 44 Pamulang. JENIUS (Jurnal Ilmiah Manajemen Sumber Daya Manusia), 3(1), 58-73.

Sutrisno, S., \& Sunarsi, D. (2019). The Effect of Work Motivation and Discipline on Employee Productivity at PT. Anugerah Agung in Jakarta. Jurnal Ad'ministrare, 6(2), 187-196.

Terry, George R. 2010. Principles of Management Alih Bahasa Winardi. Penerbit Alumni: Bandung.

Whitmore, 2002. Penelitian dan Pengembangan Karyawan, Universitas Indonesia: Jakarta. 